\title{
Effect of nitrogen supply on growth and photosynthesis of sunflower plants grown in the greenhouse
}

\author{
Inês Cechin*, Terezinha de Fátima Fumis \\ Departamento de Ciências Biológicas, Faculdade de Ciências, Universidade Estadual Paulista, CEP 17033-360, Bauru-SP, Brazil
}

Received 31 July 2003; received in revised form 27 January 2004; accepted 28 January 2004

\begin{abstract}
The effects of nitrogen availability on growth and photosynthesis were followed in plants of sunflower (Helianthus annuus L., var. CATISSOL-01) grown in the greenhouse under natural photoperiod. The sunflower plants were grown in vermiculite under two contrasting nitrogen supply, with nitrogen supplied as ammonium nitrate. Higher nitrogen concentration resulted in higher shoot dry matter production per plant and the effect was apparent from 29 days after sowing (DAS). The difference in dry matter production was mainly attributed to the effect of nitrogen on leaf production and on individual leaf dry matter. The specific leaf weight (SLW) was not affected by the nitrogen supply. The photosynthetic $\mathrm{CO}_{2}$ assimilation $(A)$ of the target leaves was remarkably improved by high nitrogen nutrition. However, irrespective of nitrogen supply, the decline in photosynthetic $\mathrm{CO}_{2}$ assimilation occurred before the end of leaf growth. Although nitrogen did not change significantly stomatal conductance (gs), high-N grown plants had lower intercellular $\mathrm{CO}_{2}$ concentration $\left(C_{i}\right)$ when compared with low-N grown plants. Transpiration rate $(E)$ was increased in high-N grown plants only at the beginning of leaf growth. However, this not resulted in lower intrinsic water use efficiency (WUE).
\end{abstract}

(C) 2004 Elsevier Ireland Ltd. All rights reserved.

Keywords: Sunflower; Nitrogen; Gas Exchange; Growth; Dry Matter Allocation

\section{Introduction}

Metabolic processes, based on protein, leading to increases in vegetative and reproductive growth and yield is totally dependent upon the adequate supply of nitrogen [1]. Both field and laboratory investigations have demonstrated that increasing the supply of nitrogen fertilizer increases growth and photosynthesis. The sensitivity of plant growth to nitrogen fertilization is of great importance in agriculture. For example, nitrogen deprivation reduces the leaf production, individual leaf area and total leaf area $[2,3]$, resulting in a reduced area for light interception for photosynthesis.

An increase in nitrogen availability results in higher leaf nitrogen content. This results in strong positive correlation between photosynthesis and leaf nitrogen content for many $\mathrm{C}_{4}$ and $\mathrm{C}_{3}$ species [4-7]. Up to $75 \%$ of leaf nitrogen is found in the chloroplasts [8,9], most of it invested in ribulose bisphosphate carboxilase alone. Consequently, lower rates

\footnotetext{
* Corresponding author. Tel.: +55-142216078; fax: +55-142216092.

E-mail address: icechin@fc.unesp.br (I. Cechin).
}

of photosynthesis under conditions of nitrogen limitation are often attributed to reduction in chlorophyll content and Rubisco activity [10-13,2].

In comparison to the large number of studies on the photosynthetic response to nitrogen supply, much less effort has been applied to understanding how this response changes with leaf age. The aim of this work was to study the effect of nitrogen supply on growth and photosynthesis. In order to verify the extent to which nitrogen supply influences photosynthesis as a function of leaf age, gas exchange measurements were made on the target leaves during most of their growth period.

\section{Materials and methods}

\subsection{Plant material and growth conditions}

Seven seeds of sunflower (Helianthus annuus L. var. CATISSOL-01), supplied by CATI (Coordenadoria de Assistência Técnica Integral) were sown in $8 \mathrm{dm}^{3}$ pots containing vermiculite. Seedlings were thinned to one per pot 
after emergency and were grown in a greenhouse under natural photoperiod. Maximum day and night temperatures were close to 30 and $20^{\circ} \mathrm{C}$, respectively.

Plants were watered with $70 \%$ of full strength nitrogen-free Long Ashton solution [14], containing either low (28.2 ppm) or high (282 ppm) nitrogen as ammonium nitrate. The plants were supplied with $300 \mathrm{~cm}^{3}$ or $400 \mathrm{~cm}^{3}$ (adult plants) of solution per pot three times a week, and with tap water on the other days.

\subsection{Growth measurements}

At approximately 7 day intervals, five plants of each level of nitrogen were selected randomly for growth measurements. Nine harvests were made in total, beginning 29 days after sowing (DAS). At each harvest, sunflower plants were divided into leaves, stem and head before been oven dried at $70{ }^{\circ} \mathrm{C}$ for at least $48 \mathrm{~h}$.

\subsection{Photosynthetic measurements}

A portable infra-red gas analyzer (LCpro, Analytical Development Company, Hoddesdon, UK) was used for measurements of photosynthesis $(A)$, stomatal conductance to water vapor (gs), transpiration $(E)$ and intercellular $\mathrm{CO}_{2}$ concentration $\left(C_{i}\right)$ at approximately 7 day intervals. Measurements were made inside the greenhouse and photosynthetic active radiation (PAR) of $1900 \mu \mathrm{mol} \mathrm{m}^{-2} \mathrm{~s}^{-1}$ was supplied by a light unit containing blue LED's at $470 \mathrm{~nm}$ and red ones at $660 \mathrm{~nm}$ mounted on the top of leaf chamber. Between 5 and $10 \%$ of the photons were blue. Photosynthesis was measured before harvesting the plants, beginning with leaf 6 (29 DAS) and including leaf 10, 14, 18 and 22 as they emerged and with an area higher than the leaf chamber $\left(6.25 \mathrm{~cm}^{2}\right)$. Leaf position is counted starting from the base of the plant to the apice. Measurements were suspended when the leaves senesced. The partial pressure of $\mathrm{CO}_{2}$ and water vapor pressure of air (entering from outside of the greenhouse) and leaving the leaf chamber, the molar air flow rate $\left(200 \mu \mathrm{mol} \mathrm{s}^{-1}\right.$, air temperature and PAR were also recorded together with photosynthetic measurements. Rates of $A$, gs, $E$ and $C_{i}$ were calculated using the equations described by von Caemmerer and Farquhar [15]. Instantaneous water use efficiency (WUE) was calculated by dividing A by E. After the measurements of photosynthesis have been taken, the target leaves were used for specific leaf weight (SLW) calculation according to [16] and individual leaf dry mass determination.

\section{Statistical analysis}

The data were submitted to Student's $t$-Test for Independent Samples by using SPSS/PC for Windows. Linear Regressions were fitted using Microcall Origin.

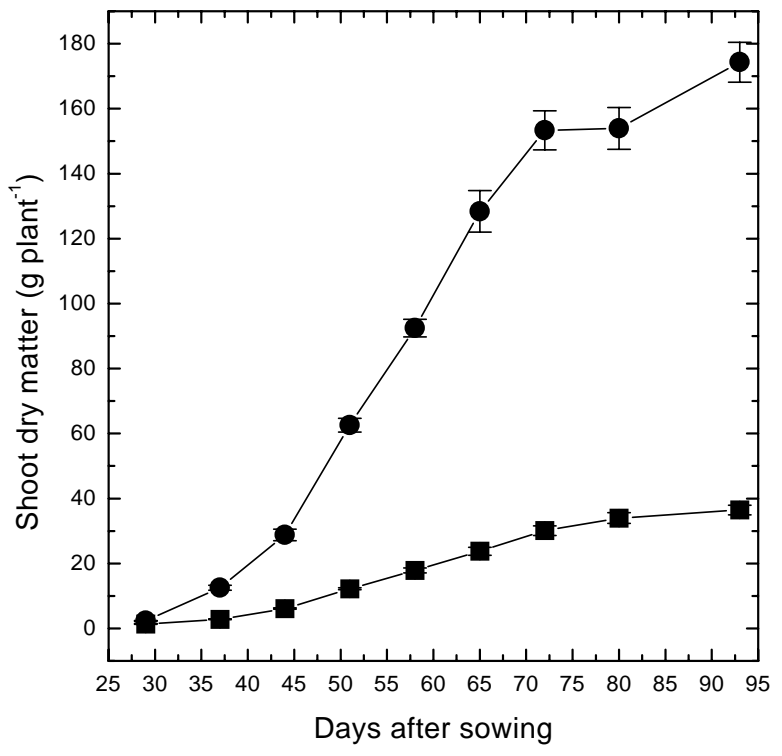

Fig. 1. Shoot dry matter of plants grown at low ( $)$ or high; $(\mathbf{O})$ nitrogen supply. Means \pm S.E. of five replicates are given.

\section{Results and discussion}

High nitrogen supply did not affect significantly the time of head appearance or anthesis of sunflower plants in this study (data not shown). However, the sunflower height ${ }^{1}$ and shoot dry matter in high $\mathrm{N}$-grown plants were significantly higher from 37 and 29 DAS onwards, respectively, compared to low N-grown plants (Fig. 1). Magnitude of the difference in shoot dry matter production between low and high N-grown plants became progressively more marked at each harvest. By the final harvest (93 DAS), shoot dry matter production of high $\mathrm{N}$-grown plants was nearly four-fold that of low N-grown plants. Dry matter of the above ground organs was significatively lower in plants grown under low nitrogen supply (Fig. 2). At the final harvest, the amount of dry matter for stem, leaves and head reached 21, 14 and $25 \%$ of the high $\mathrm{N}$-grown plants, respectively. The large difference in leaf dry matter between low and high N-grown plants is a result of an effect of nitrogen on final leaf production per plant (25.4 and 31.0 for low and high nitrogen, respectively; data not shown) and in individual leaf dry mass (Fig. 3).

A high sensitivity of leaf growth to nitrogen availability has been demonstrated in many studies. Trapáni et al. [17] showed that the leaf size is very responsive to nitrogen supply. The leaf size been largely a result of cell production and cell expansion. However, Roggatz et al. [18] demonstrated that the effect of nitrogen deficiency depends on the developmental status of the leaf when nitrogen stress is imposed. Deprivation of nitrogen in the earlier stages of leaf development when cell division still taking place resulted

\footnotetext{
1 These data are available via the eletronic address quoted on the front page of this article.
} 

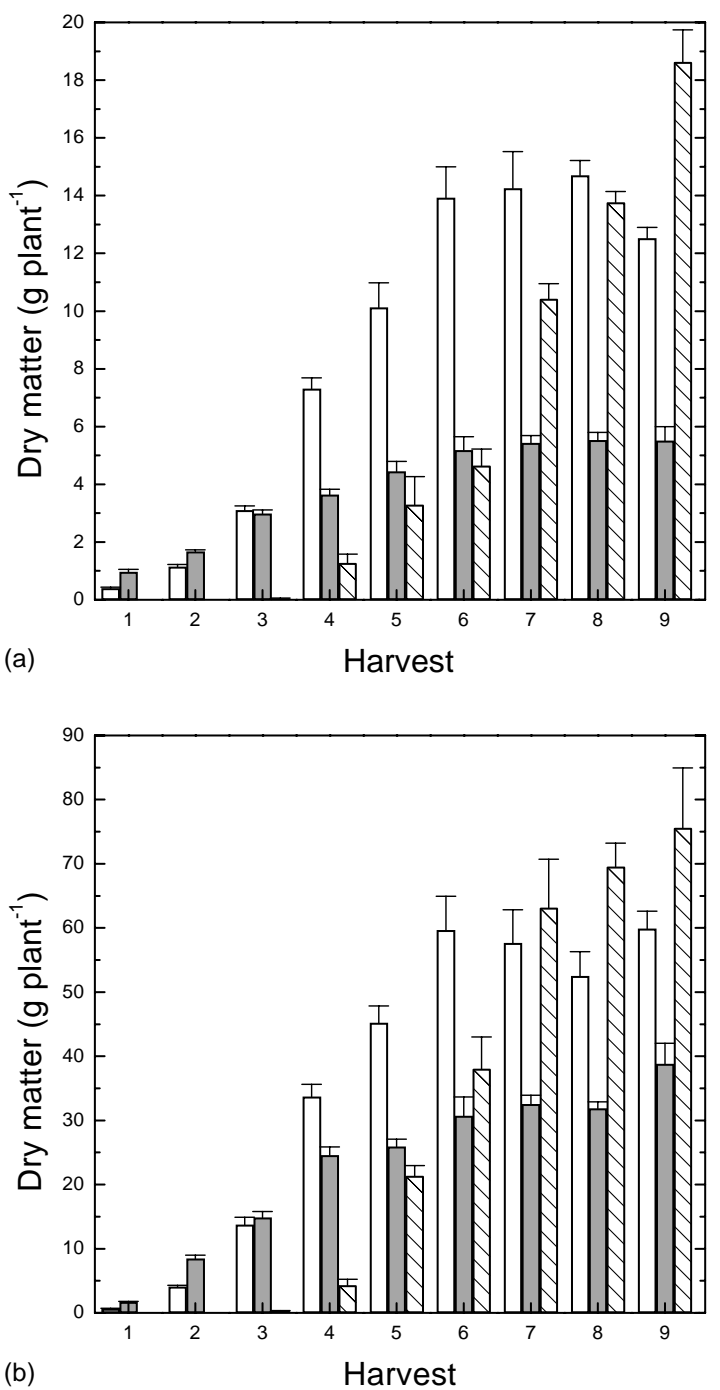

Fig. 2. Shoot dry matter allocation in plants grown at (a) low or (b) high nitrogen supply. $(\square)$, stem; $(\square)$, leaves; $(\square)$, head. Bars are S.E. of mean of five replicates. Note that scales are different between nitrogen treatments.

in greater reduction in final leaf size. At this stage, a reduction in the number of cells produced accounted for approximately $80 \%$ of the reduction in final leaf size. In this study, low nitrogen supply resulted in lower individual leaf dry matter of the target leaves (Fig. 3). Although the nitrogen deficiency was induced at the seedling emergency, the reduction in individual leaf dry matter is greater in the younger leaves. It is possible that for the older leaves which started to initiate their growth during the seedling phase had some nutrition from the cotyledons since they remained green for long period. In wild species and crops each successive leaf tends to be larger up to a certain point beyond which the size is progressively reduced [19]. However, in sunflower plants grown under low nitrogen supply this pattern is less apparent compared to high nitrogen supply (see Footnote 1).
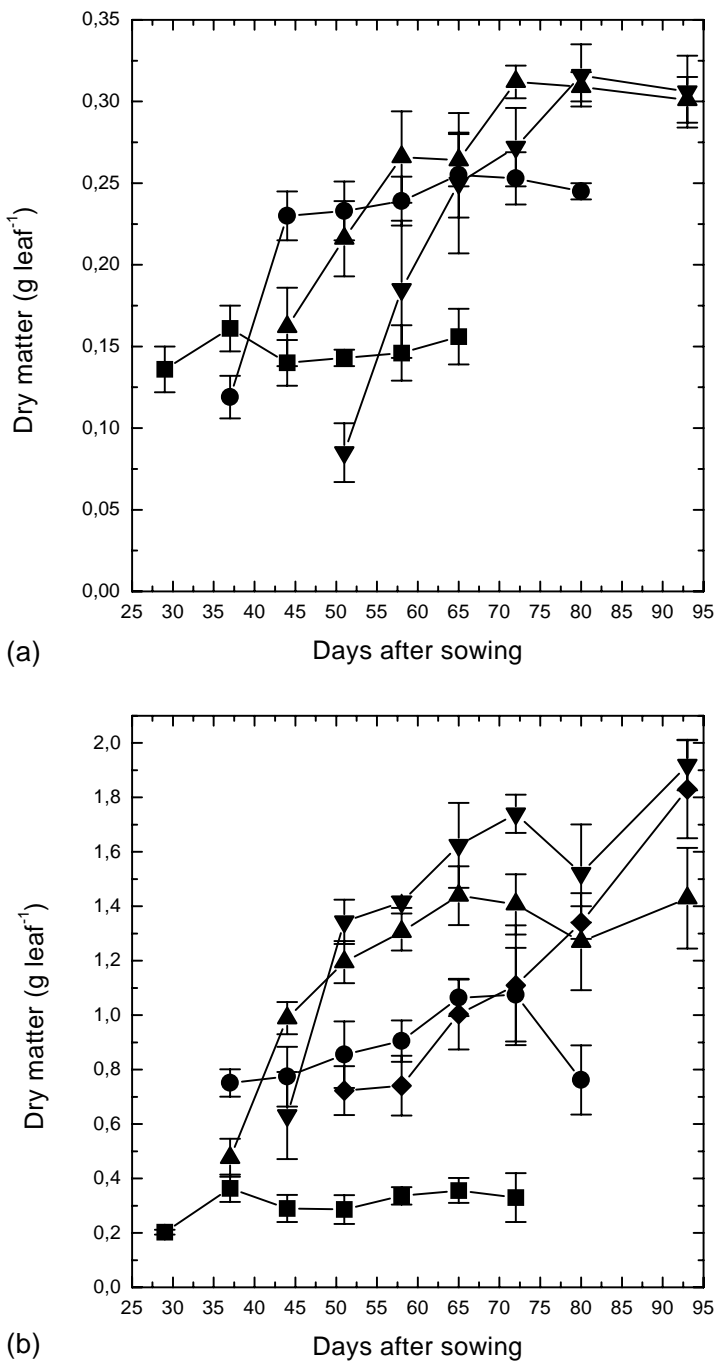

Fig. 3. Dry matter of target leaves of sunflower plants grown at (a) low or (b) high nitrogen supply over the growth period. Symbols: $(\boldsymbol{\square})$, leaf 6; $(\boldsymbol{O})$, leaf 10; $(\boldsymbol{\Delta})$, leaf 14; $(\boldsymbol{\nabla})$, leaf 18; $(\boldsymbol{\diamond})$, leaf 22. Points are means \pm S.E. of five replicates unless other wise stated. $n=4$ for leaf 6 and leaf 10 at sixth and eighth harvest, respectively. Note that the scales are different between nitrogen treatments.

Specific leaf weight was unaffected by nitrogen supply in spite of the large response in leaf dry matter of the target leaves (see Footnote 1), suggesting that leaf thickness was not altered. The lack of an effect of nitrogen on SLW allows the photosynthetic rates on an area or weight basis to be directly comparable between low and high $\mathrm{N}$-grown plants. Photosynthetic capacity of a leaf increases to a maximum at or before full leaf expansion, followed by a linear decline with time $[20,21]$. In this study, the decline in photosynthesis occurred before the end of leaf growth, independent of nitrogen supply (Figs. 3 and $4 \mathrm{a}, \mathrm{b}$ ). Photosynthetic $\mathrm{CO}_{2}$ assimilation of the target leaves was higher in high $\mathrm{N}$-grown plants and were maintained higher nearly throughout the growth period, except for the last 2-3 harvests where target leaves 10-18 under low and high nitrogen supply had similar rates of photosynthesis. 

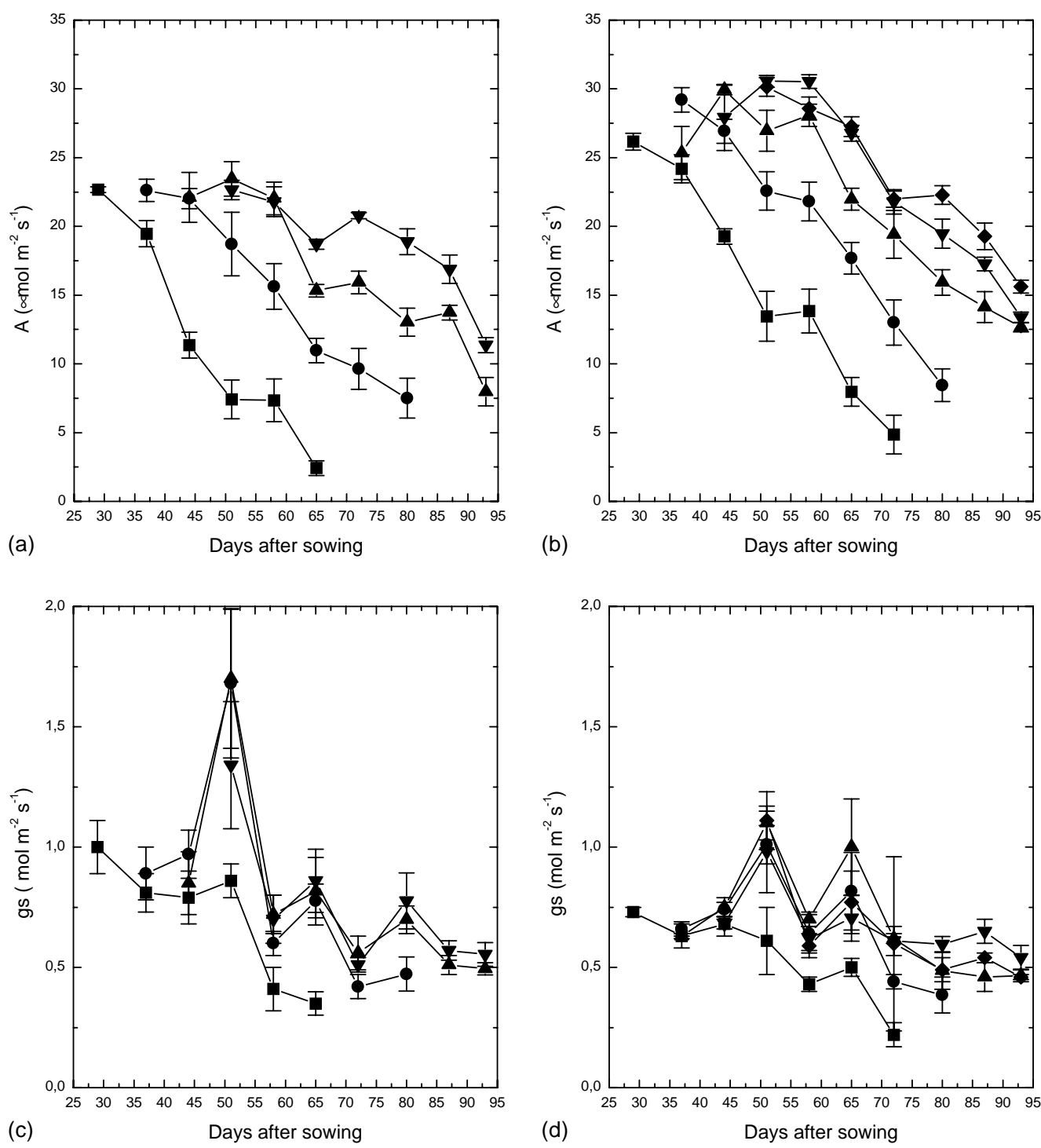

Fig. 4. Changes with time in photosynthesis $(A)$ and stomatal conductance to water vapor (gs) of target leaves of sunflower plants grown at (a, c) low or (b, d) high nitrogen supply. Symbols are as in Fig. 3. Points are means \pm S.E. of five replicates unless other wise stated. $n=4$ for leaf 6 and leaf 10 at sixth and eighth harvest, respectively.

There are contradictory data in the literature about the effect of nitrogen on gs. Lower rates of gs in low N-grown plants have been reported [22,23]. On the other hand, opposite effect [24] or no effect [12,25] by nitrogen are also reported. In this experiment, lower nitrogen supply did not change significantly gs of the target leaves, except for leaf 6 which had higher gs than leaf 6 of well nourished sunflower plants (Fig. $4 \mathrm{c}$ and d). However, gs declined with leaf age for both low and high-N grown plants.

Parallel changes in A and gs are reflected in a relatively constant $C_{i}$ [21] and interpreted as an effect of increased intercellular $\mathrm{CO}_{2}$ concentration on stomata behavior, thus maintaining a balance between stomatal and non-stomatal limitations of photosynthesis. During leaf aging of sunflower plants grown at low or high-N supply gs also declined (Fig. 4c and d). However, this was not reflected in a relatively constant $C_{i}$ (Fig. 5c and d). Thus, in sunflower plants the fall in A with leaf age is not fully accounted to stomatal control but due to a decrease in the photosynthetic capacity as a consequence of photosynthetic apparatus degradation. The absence of any detectable effect of nitrogen supply on gs is consistent with the results and hypothesis reported by Grassi et al. [25] that nitrogen is not related to stomatal conductance. Although nitrogen supply did not affect significantly gs, high $\mathrm{N}$-grown plants had lower $C_{i}$ than low $\mathrm{N}$-grown plants throughout most the experimental period (Fig. 5c and d). Higher $C_{i}$ has been interpreted as an indication of higher mesophyll resistance. Although leaf nitrogen was not determined in this study, it seems that in sunflower plants lower rates of photosynthesis are related to reduced mesophyll capacity for net assimi- 

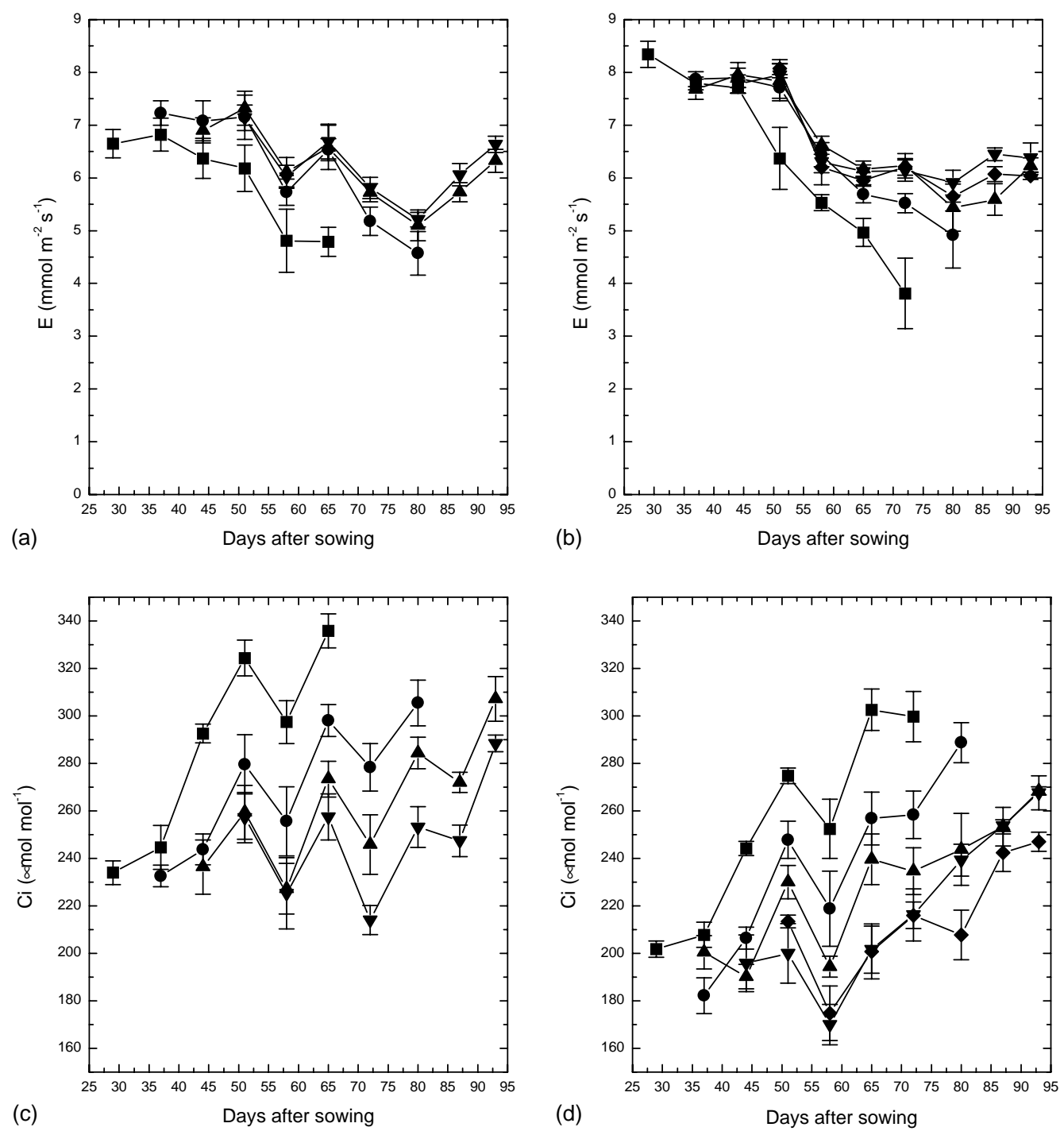

Fig. 5. Changes with time in transpiration $(E)$ and intercellular $\mathrm{CO}_{2}$ concentration $\left(C_{i}\right)$ of target leaves of sunflower plants grown at (a, c) low or (b, d) high nitrogen supply. Symbols are as in Fig. 4. Points are means \pm S.E. of five replicates unless other wise stated. $n=4$ for leaf 6 and leaf 10 at sixth and eighth harvest, respectively.

lation rates at the cellular level as a consequence of lower nitrogen availability for investment into photosynthetic apparatus.

Under high nitrogen supply the amount of water lost through $E$ was higher than under low nitrogen supply only at the beginning of leaf growth of the target leaves (Fig. 5a, b). However, the observed increase in $E$ in high $\mathrm{N}$-grown plants did not result in lower WUE (see Footnote 1) because of higher rates of photosynthesis.

A linear relationship between $A$ and gs represents the contribution of gs on photosynthetic $\mathrm{CO}_{2}$ assimilation. A similar relationship was observed in leaves of sunflower plants in this study (Fig. 6). However, the slope of the relationship between the two variables was much steeper in high $\mathrm{N}$-grown plants than low $\mathrm{N}$-grown plants, a further evidence that the effect of low nitrogen on photosynthesis is not attributed to an effect of nitrogen on gs but to other constraints on the $\mathrm{CO}_{2}$ photosynthetic assimilation capacity. The relationship between $\mathrm{A}$ and $C_{i}$ had an inverse behavior than $A$ and gs for both low and high N-grown plants (Fig. 7). As the photosynthetic rates of the target leaves declined with time, the $\mathrm{CO}_{2}$ concentration in the sub-stomatal cavity of the leaf increased.

Taking all together, high nitrogen supply had a significant stimulatory effect on shoot dry matter production and on photosynthetic activity of sunflower plants. Moreover, the higher rates of photosynthesis were accompanied by an increase in leaf dry matter, thus increasing the total assimilatory area. The importance of nitrogen on leaf growth and as a component of photosynthetic apparatus, an adequate supply is necessary for growth and photosynthesis stimulation. 


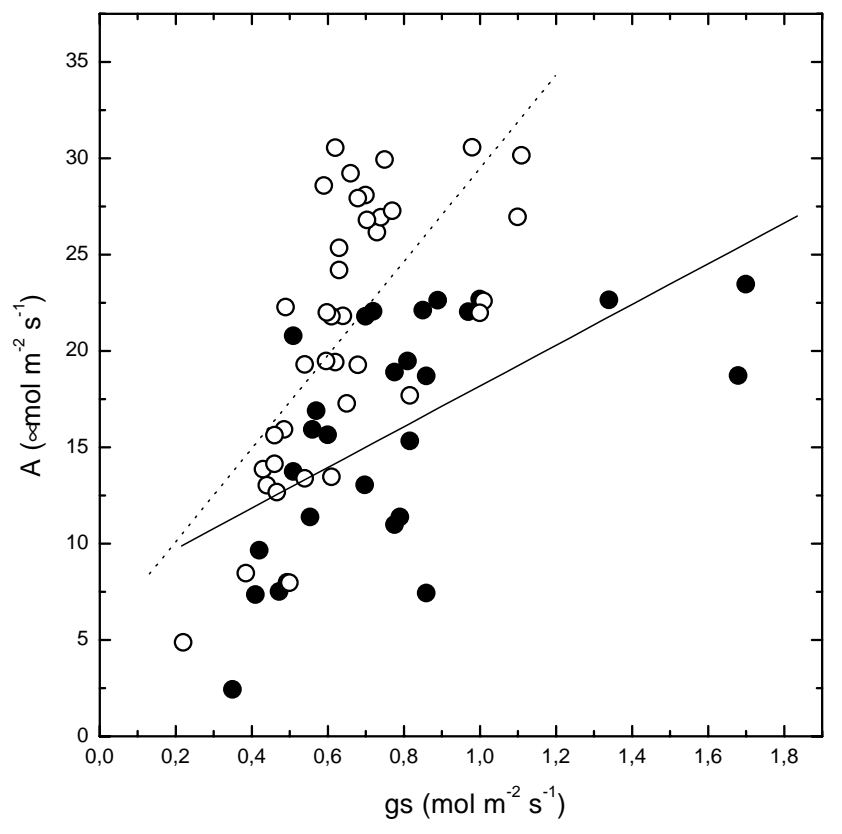

Fig. 6. Relationship between photosynthesis $(A)$ and stomatal conductance to water vapor (gs) of sunflower plants grown at (closed symbols) low or (opened symbols) high. Data from all the growth period are presented. Each point represents the mean of five replicates taken from the target leaves. Standard errors of the means are shown in Fig. 7. Regression equations are: closed symbols, $y=7.614+10.569 x ; R=0.589$. Opened symbols, $y=5.254+24.224 x ; R=0.680 ; P<0.001$.

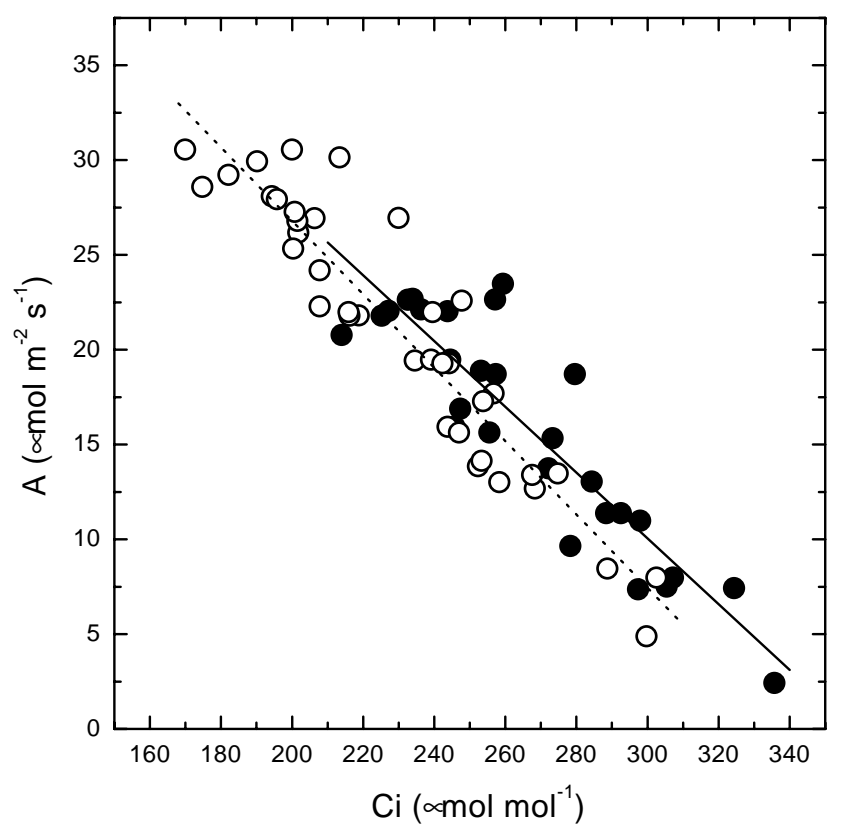

Fig. 7. Relationship between photosynthesis $(A)$ and intercellular $\mathrm{CO}_{2}$ concentration $\left(C_{i}\right)$ of sunflower plants grown at (closed symbols) low or (opened symbols) high. Data from all the growth period are presented. Each point represents the mean of five replicates taken from the target leaves. Standard errors of the means are shown in this figure . Regression equations are: closed symbols, $y=62.065-0.173 x ; R=0.902$. Opened symbols, $y=65.523-0.194 x ; R=0.941 ; P<0.001$.

\section{Acknowledgements}

One of the authors (IC) thanks the Brazilian agency FAPESP for financial support.

\section{References}

[1] D.W. Lawlor, Carbon and nitrogen assimilation in relation to yield: mechanisms are the key to understanding production systems, J. Exp. Botany 53 (2002) 773-787.

[2] V.R. Toth, I. Meszkaros, S. Veres, J. Nagy, Effects of the available nitrogen on the photosynthetic activity and xanthophyll cycle pool of maize in field, J. Plant Physiol. 159 (2002) 627-634.

[3] J. Vos, H. Biemond, Effects of nitrogen on development and growth of the potato plant. 1. Leaf appearance, expansion growth, life spans of leaves and stem branching, Ann. Botany 70 (1992) 27-35.

[4] C. Field, H.A. Mooney, The photosynthesis-nitrogen relationship in wild plants, in: T.J. Givnish (Eds.), On the Economy of Plant Form and Function, Cambridge University Press, 1986, pp. 25-55.

[5] J.R. Evans, Photosynthesis and nitrogen relationship in leaves of $\mathrm{C}_{3}$ plants, Oecologia 78 (1989) 9-19.

[6] S.C. Huber, T. Sugiyama, R.S. Alberte, Photosynthetic determinants of growth in maize plants: effects of nitrogen nutrition on growth, carbon fixation and photochemical features, Plant Cell Physiol. 30 (1989) 1063-1072.

[7] D.J. Connor, A.J. Hall, V.O. Sadras, Effect of nitrogen content on the photosynthetic characteristics of sunflower leaves, Aust. J. Plant Physiol. 20 (1993) 251-263.

[8] R.H. Brown, A difference in nitrogen use efficiency in $C_{3}$ and $C_{4}$ plants and its implications in adaptation and evolution, Crop Sci. 18 (1978) 93-98.

[9] R. Hak, U. Rinderle-Zimmer, H.K. Lichtenthaler, L. Natr, Chlorophyll $a$ fluorescence signatures of nitrogen deficient barley leaves, Photosynthetica 28 (1993) 151-159.

[10] J.R. Evans, I. Terashima, Effects of nitrogen nutrition on electron transport components and photosynthesis in spinach, Aust. J. Plant Physiol. 14 (1987) 59-68.

[11] J.I. Fahl, M.L.C. Carelli, J. Vega, A.C. Magalhães, Nitrogen and irradiance levels affecting net photosynthesis and growth of young coffee plants, J. Horticult. Sci. 69 (1994) 161-169.

[12] A.L. Fredeen, J.A. Gamon, C.B. Field, Responses of photosynthesis and carbohydrate-partitioning to limitations in nitrogen and water availability in field-grown sunflower, Plant Cell Environ. 14 (1991) 963-970.

[13] A.S. Verhoeven, W.W. Demmig-Adams, Adams III, Enhanced employment of the xanthophyll cycle and thermal energy dissipation in spinach exposed to high light and $\mathrm{N}$ stress. Plant Physiol. 113 (1997) 817-824.

[14] E.J. Hewitt, Sand and Water Culture Methods Used in the Study of Plant Nutrition, Commonwealth Agricultural Bureaux, Farnham Royal, 1966, 547pp.

[15] S. Von Caemmerer, G.D. Farquhar, Some relationships between the biochemistry of photosynthesis and gas exchange of leaves, Planta 153 (1981) 376-387.

[16] N.R. Chiariello, H.A. Mooney, K. Williams, Growth, carbon allocation and cost of plant tissues, in: R.W. Pearcy, J. Ehleringer, H.A. Mooney, P.W. Rundel (Eds.), Plant Physiological Ecology: Field, Methods and Instrumentation, Chapman \& Hall, 1991, pp. 327-365.

[17] N. Trapáni, A.J. Hall, M. Weber, Effects of constant and variable nitrogen supply on sunflower (Helianthus annuus L.) leaf cell number and size, Ann. Botany 84 (1999) 599-606.

[18] U. Roggatz, A.J.S. Mcdonald, I. Standerberg, U. Schurr, Effect of nitrogen deprivation on cell division and expansion in leaves of Ricinus communis L., Plant Cell Environ. 22 (1999) 81-89. 
[19] A.H. Fitter, R.K.M. Hay, Environmental Physiology of Plants, Academic Press, 1987 pp.

[20] R.K.M. Hay, A.J. Walker, An Introduction to the Physiology of Crop Yield, Longman Scientific \& Technical, 1989, p. 292.

[21] I.E. Henson, C.R. Jensen, N.C. Turner, Influence of leaf age and light environment on the gas exchange of lupins and wheat, Physiol. Plant. 79 (1990) 15-22.

[22] M.R. Broadley, Escobar-Gutiérrez, A. Burns, I.G. Burns, What are the effects of nitrogen deficiency on growth components of lettuce? New Phytol. 147 (2000) 519-526.
[23] Z.P. Shangguan, M.A. Shao, J. Dyckmans, Nitrogen nutrition and water stress effects on leaf photosynthetic gas exchange and water use efficiency in winter wheat, Environ. Exp. Botany 44 (2000) 141149.

[24] S. Ciompi, E. Gentili, L. Guidi, G.F. Soldatini, The effect of nitrogen deficiency on leaf gas exchange and chlorophyll fluorescence parameters in sunflower, Plant Sci. 118 (1996) 177-184.

[25] G. Grassi, P. Meir, R. Cromer, D. Tompkins, P.G. Jarvis, Photosynthetic parameters in seedlings of Eucalyptus grandis as affected by rate of nitrogen supply, Plant Cell Environ. 25 (2002) 1677-1688. 